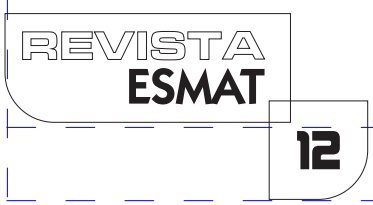

\title{
PRINCÍPIOS VIDA E RESPONSABILIDADE: O AGIR HUMANO NA CONTEMPORANEIDADE A PARTIR DAS IDEIAS DE HANS JONAS
}

PRINCIPLES OF LIFE AND RESPONSIBILITY OF HANS JONAS: HUMAN ACTION IN CONTEMPORANITY

Patrícia Medina

Pedagoga e bacharel em Direito. Mestre em Administração de Sistemas Educacionais. Doutora em Educação: Cultura e Processos Educacionais. Professora do curso de Pedagogia da UFT e Mestrado Profissional Interdisciplinar em Prestação Jurisdicional e Direitos Humanos (UFT/ESMAT). Editora Científica da Revista Adsumus e Editora Assistente da Revista ESMAT. Email: patriciamedina@uft.edu.br

Gustavo Paschoal Teixeira de Castro Oliveira

Mestre em Direito. Professor do curso de Direito e Programa de Mestrado Profissional Interdisciplinar em Prestação Jurisdicional e Direitos Humanos (UFT/ESMAT). E-mail: gustavopaschoall @gmail.com

Marcia Mesquita

Mestre em Prestação Jurisdicional e Direitos Humanos (UFT/ESMAT). Graduada em Serviço Social pela Pontifícia Universidade Católica de Goiás. Professora e coordenadora do curso de Serviço Social do Centro Universitário Luterano de Palmas (CEULP/NLBRA). Analista técnica do Tribunal de Justiça do Estado do Tocantins.E-mail: asmarciamv@gmail.com

Graciela Maria Barros

Mestranda do Programa de Mestrado Profissional Interdisciplinar em Prestação Jurisdicional e Direitos Humanos (UFT/ESMAT). Graduada em Direito pela Universidade Federal do Tocantins e em Letras pela Universidade Luterana do Brasil. Pós-Graduada em Língua Portuguesa pela Faculdade Darwin e em Direito e Processo Constitucional na Universidade Federal do Tocantins. Servidora pública federal. E-mail: gracielabarros@mail.uft.edu.br

\section{RESUMO}

Trata-se de estudo teórico vinculado à linha de pesquisa Gestão, Cidades e Sustentabilidade, da Universidade Federal do Tocantins (UFT), dedicado a reconstruir concepções acerca do tema "Agir Humano na Contemporaneidade numa Abordagem Expositiva das Ideias de Hans Jonas, relativamente aos princípios da ética da responsabilidade. A estratégia teórico-metodológica seguiu o fluxo do círculo hermenêutico constitutivo do método fenomenológico das ideias apresentadas nas 
duas obras "Princípio Vida" (2004) e "Princípio Responsabilidade" (2006). As reflexões foram apresentadas na forma de oficina no $\vee$ Congresso Internacional de Direitos Humanos do Mestrado Profissional Interdisciplinar em Prestação Jurisdicional e Direitos Humanos pelos professores e duas alunas da disciplina Ética Profissional e Função Social do Poder Judiciário do referido curso e possibilitaram concluir que somente uma ética fundada na vida, na manutenção e na custódia da existência pode ter um sentido efetivo, pois a necessidade/precisão da ética será exponencialmente maior quanto maiores forem os poderes do agir humano que esta deverá regular.

PALAVRAS-CHAVE: Ética; Vida; Responsabilidade; Hans Jonas

\section{ABSTRACT}

This is a theoretical study linked to the research line Management, Cities and Sustainability of the Universidade Federal do Tocantins (UFT) dedicated to rebuilding conceptions about the theme human activity nowadays in expository approach of Hans Jonas ideas regarding the ethics of principles of responsibility. The theoretical and methodological strategy followed the flow of hermeneutical circle of the phenomenological method of the ideas presented in the two works Principle Life (2004) and Principle of Responsibility (2006). The reflections were presented as workshop at the $\mathrm{V}$ International Congress of Human Rights Master Interdisciplinary Professional in the judging Provision and Human Rights by professors and two students of the subject Professional Ethics discipline and Social Role of the Judiciary of that course and led us to conclude that only an ethical founded in life, maintenance and custody of existence can be an effective way because the need / accuracy of ethics will be exponentially bigger as the power of human action that it should regulate.

KEYWORDS: Ethics; Life; Responsibility; Hans Jonas.

\section{INTRODUÇÃO}

Na contemporaneidade, a ética abriga três grandes reflexões: i) como devemos agir sob a denominação de ética das virtudes; ii) o certo e o errado das condutas via teorias morais; iii) e a ética interdisciplinar e aplicada a preceitos, problemas de ordem valorativa de grupos sociais e profissionais. A ética da responsabilidade na perspectiva de Hans Jonas (1903-1993) que orientará este escrito se encontra desenvolvida nas obras Princípio Vida e Princípio Responsabilidade e tem como objetivo apresentar descritivamente os fundamentos da responsabilidade como princípio necessário ao 
enfrentamento da questão-problema sobre a possibilidade, ou não, de instituir uma nova forma de convivência do homem com à dos outros homens, de modo a garantir a vida em todas as suas formas nos contornos biológicos, compreendida nos limites da química dos compostos de carbono.' $\bigcirc$ tema foi inicialmente explorado pela tese intitulada "A relação homem-natureza, a fenomenologia do cuidar e a dimensão formativa" e tem sido objeto de reflexões e ampliações como foi nessa oportunidade com alunos da disciplina Ética profissional e função social do poder judiciário, do Mestrado Profissional Interdisciplinar em Prestação Jurisdicional e Direitos Humanos, e resultou neste artigo e na oficina já mencionada.

A justificativa da reflexão se assenta no momento histórico em que a humanidade vive e combina o que genericamente é denominado de crise de ordem ético-moral, pois envolve o agir, mas também avança sobre o existir. Para todos os contextos da existência, destaca-se a preocupação da avaliação sobre os resultados das ações e inações humanas e suas repercussões nas condições objetivas da vida. Essa situação pressupõe aceitar que há uma relação direta entre os grupos humanos que criam, desenvolvem, planejam e testam as novas tecnologias, e as consequências destas sobre a vida. Ademais, que a moral subjetiva tem se provado incapaz de orientar o domínio da técnica pelo próprio homem. Mais propriamente, as normas morais não substituem o fundamento que uma ética precisa ter.

Repetidamente encontramos distinguidos os termos ética, moral e direito. Embora haja um esforço para diferenciá-los, os seus sentidos estão fortemente vinculados, porque moral e direito se assentam em regras que tendem a prever e prescrever ações humanas. A moralidade independe de fronteiras geográficas, constitui regras que as pessoas assumem para garantir um bem-viver ou uma identidade grupal e social, mesmo que elas não se relacionem, tenham afinidade ou sequer se conheçam. Pode-se expressar concretamente como quando os homens acatam os costumes de determinada região, quando migram como trajar determinada indumentária ou guardar o dia de determinado santo as quais são internalizadas e expressas pela cultura e educação, cotidianamente aplicadas pelas pessoas. $\bigcirc$ Direito, por sua vez, institui o regramento social, delimita as fronteiras geográficas territoriais, pois se materializa na forma de leis, e estas têm vigência em determinado território. Assim, é possível afirmar que moral e direito são regras práticas. (MEDINA, 20 I I).

A ética constitui o estudo geral e teórico do que é bom ou mau, e procura por justificativas a essas regras morais e legais. Ética constitui o conjunto de conhecimentos retirados da investigação racional, fundamentada, científica e teórica do comportamento humano, logo, propõe-se a explicar as regras morais. Ética é a teoria que explica. Ética é uma reflexão sobre a moral.

\footnotetext{
'Excluem-se as reflexões sobre todas as formas possíveis de vida no universo, até mesmo a
} baseada em silício. 
O que caracteriza a ética é justamente a reflexão sobre a ação humana, aspecto que nos permite assegurar que é antropocentrada, ou seja, diz respeito ao relacionamento direto intra-humano e até o de cada humano consigo mesmo. Como princípio, a ética tem de haver porque os homens agem, e "a ética existe para ordenar suas ações e regular seu poder de agir" (JONAS, 2006, p. 65). Ademais, há de se considerar que a sua necessidade será exponencialmente maior quanto maiores forem os poderes do agir humano, ou seja, aquilo que ela deve ou deverá regular. Na contemporaneidade, essas possibilidades humanas têm sido ampliadas pela capacidade de reconfigurarem o mundo e a vida pela tecnologia.

A Tecnologia é compreendida como a materialização da técnica. A tecnologia constitui a aplicação da ciência; suporta e lida com a inteira responsabilidade dos inconvenientes, dos erros e das impropriedades do que vemos como progresso técnico. Esse entendimento tem sua referência na filosofia da técnica de Gilbert Simondon ( 1924- 1989), que afirma:

A oposição entre a cultura e a técnica, entre o homem e a máquina, é falsa e sem fundamento; ela esconde apenas ignorância ou ressentimento. Ela mascara atrás de um humanismo fácil uma realidade rica em esforços humanos e em forças naturais e que constitui o mundo dos objetos técnicos, mediadores entre a natureza e o homem. (SIMONDON, 1958, Introdução, sp).

E congrega da tese de Martin Heidegger de que a técnica não é um simples meio estabelecido pelos humanos para alcançar fins postos por estes, mas que o homem é funcionário da técnica, a primeira e fundamental matéria-prima. Contudo, ele é capaz, pode lançar um olhar à essência da técnica e vislumbrar ali o perigo, mas também nela vislumbrar as condições do que o salva. Entretanto, esse perigo que jaz na essência da técnica é tanto mais lesivo quanto mais se apresenta sob a aparência de progresso (Heidegger, 2008).

progresso é visível em todas as modalidades do saber humano. Esses saberes possuem a capacidade de serem acumuláveis e transmissíveis, constituindo, assim, patrimônio na ciência, na técnica, no meio social e econômico, na segurança, no conforto, na diversidade cultural, na ampliação do acesso aos direitos que, rearranjados, resultaram em novos hábitos. Parece haver em todos esses aspectos certo progresso em direção ao melhor. Mas há um preço a pagar.

A natureza artificial que o homem criou para si, ou seja, as cidades, estas se destinavam a protegê-lo, e não a se expandirem. Originalmente as cidades abrigavam o homem da natureza. Com as cidades, o homem estabeleceu um novo equilíbrio interno dentro de outro maior: a natureza. Desse modo, o humano acreditou que a natureza era permanente, quase imutável. Já as cidades alargavam-se, modificavam-se e, como artefato claramente distinto da natureza, o mundo social ficou confiado aos cuidados do homem, ao domínio e às responsabilidades humanas. Nesse modelo 
cultural, a natureza não constitui responsabilidade humana. Ela se cuida e, de muitas formas, toma conta, guarda, cuida o homem, pois provê tudo de que ele precisa. Diante da natureza, o homem usa suas capacidades próprias: inteligência, inventividade, trabalho, técnica, mas não ética.

É o enfrentamento reflexivo-propositivo a essa questão que Hans Jonas promove nas duas obras recém-mencionadas e que pretendemos objetivamente apresentar.

\section{2ÉTICA}

A palavra ética tem sua origem em ethos, e possui duas grafias e dois distintos sentidos. Há nuanças. No primeiro significado, pode assumir o sentido de um lugar constante, de acolhimento, uma guarida. Um ambiente no qual constituirá seus costumes e hábitos, seu agir. Pode-se dizer que esse espaço é construído, portanto, continuamente reconstruído, uma vez que nunca a casa (do ethos) está pronta, mas permanentemente aberta ao homem. $O$ segundo significado diz respeito a um comportamento resultante de um constante repetir dos mesmos atos, não decorrente de uma necessidade natural, mas contrário ao impulso. Aqui, ethos é o processo da constituição de um hábito ou a disposição permanente de agir de determinado modo. Assim, o modo de agir do homem é a expressão de sua ética que, para tanto, deve exprimir a articulação entre o ethos como caráter e ethos como hábito, e se distende tanto como espaço de realização, superfície, local onde mora, como lugar de sua ação, de práxis. (MEDINA, 20 I I , p. 59)

O imbricamento dessas duas acepções adquire os atributos de uma fusão circular, na qual a natureza, a superfície habitada, encontra-se inter-relacionada com a nossa cultura. A natureza precede temporalmente a cultura e, ainda mais, institui o substrato, a base indispensável às manifestações culturais, à existência humana.

Posições da Biologia e das demais Ciências da Terra, nos últimos 50 anos, têm advertido acerca de um tempo que se assemelha muito àqueles de rupturas nos processos evolutivos; épocas marcadas por extinções em grande escala. Afirmam que a natureza está doente e que a doença possui como causa a ideia de progresso, embasada no entendimento de que os recursos da terra são infinitos como infinito é também o futuro. A outra dimensão é a de que estamos também confrontados a demonstrar deveres com os demais seres, como postula Jonas.

Hans Jonas nasceu em Mönchengladbach, na Alemanha. Sua vida intelectual pode ser demarcada em três fases concretamente identificáveis: a elaboração da sua tese sobre a Gnose no Cristianismo primitivo, defendida, em 1931, sob a orientação de Rudolf Karl Bultmann ( I 884- 1976), cujas marcas se perpetuam nos dois outros escritos: a publicação, em 1966, da obra intitulada O Princípio Vida: fundamentos para uma biologia filosófica, e, em 1979, na obra O Princípio Responsabilidade: ensaio de uma ética para a civilização tecnológica, que culmina na construção teórica que apresentava na obra anterior. 
Viveu a iminência da morte nas duas grandes guerras mundiais, mas se inquietou com a vida, como expressou emblematicamente no desfecho da obra O Princípio Vida,

[...] e pela continuidade do espírito com o organismo e do organismo com a natureza, a ética passa a ser uma parte da filosofia da natureza [...]. Seja qual for a qualidade moral que possa entrar na relação entre eu e mundo, ela não pode ter sua origem a não ser no próprio eu (JONAS, 2004, epílogo).

Toda a obra é um chamado à necessidade de se repensar a vida humana, tendo como ponto de partida os parâmetros para a construção de uma filosofia da biologia, a partir do alcance que os temas da biologia tem. O Princípio Vida foi escrito durante a fase em que era professor universitário em Nova lorque, na década de 1955. A frase anteriormente transcrita resume a obra que se ocupa em expor o erro, que é isolar, destacar ou separar o homem do restante da natureza.

Nirenberg historiador da Universidade de Chicago afirma sobre a biografia de Jonas que ele trata

de uma ética profundamente psicossomática, uma ética na qual o organismo é constantemente obrigado a jogar seu próprio ser em defesa das verdades essenciais por que vive. Não só esta tonalidade ética cada página da história de Jonas é a vida, ela também fornece a substância da filosofia que o tornou famoso. (2008, p. 5)

E segue alegando que os seus escritos influenciaram objetivamente o nascimento do moderno movimento ambiental e forneceram os fundamentos filosóficos para sua manifestação política mais eficaz, qual seja, o Partido Verde alemão.

Na obra Princípio Vida, a descrição da vulnerabilidade das condições da vida é apresentada sob o enfoque da frágil distinção entre orgânico e espiritual. Ante a ameaça de a Terra continuar a ser o lugar originário da vida, impõe-se a exigência de uma nova relação homem-natureza apresentada a partir da ética da responsabilidade.

O cenário atual clama por um novo sentido ético por causa dessa centralidade que a tecnologia e a ideia de progresso ocupam agora na subjetividade, nos fins da vida humana, se há condição de consciência que se desenvolve mundialmente (embora em parâmetros insuficientes), e afirma que, se levarmos adiante o modelo de desenvolvimento adotado, poderemos chegar a uma situação de irreversibilidade para a natureza e, por conseguinte, da vida. Há também a necessidade de que o comportamento humano se torne objeto de

dever de proteger a premissa básica de todo o dever, ou seja, precisamente a presença de meros candidatos a um universo moral no mundo físico do futuro; isso significa, entre outras coisas, conservar o mundo físico de modo que as condições para tal presença permaneçam intactas; e isso significa proteger a sua vulnerabilidade diante de uma ameaça dessas condições (JONAS, 2004, p. 45). 
O homem é ser vivo no mundo, nunca separado de seus objetos, porque o próprio movimento requerido para a compreensão é envolvente, universal; por isso, abrange a globalidade da experiência do homem no mundo. Por consequência, não é viável, num sentido duradouro, ao homem dominar, subjugar a natureza, a Terra, pois sempre estará inserido na dinâmica do mundo. Na história de sua evolução, o todo tecnológico pleiteia que os humanos sejam em igual tempo sujeitos e objetos, causa e finalidade, escopo e produto.

Já há um consenso de que a interface - a ligação, o vínculo humano com o ambiente natural - se exibe complexa e grave porque dela decorre uma terrível degradação das condições de manutenção da existência humana no Planeta. A relação é comumente designada pela expressão "crise ambiental", e as implicações são de ordem sistêmica, aqui compreendida como o envolvimento da totalidade das dimensões da vida. Estas envolvem a percepção de valores, cujo enfoque de base econômica se estende para além da dinâmica dos negócios e passam a dar sentido à vida, modelando as instituições, organizações sociais e os homens, com as mesmas premissas do mercado de consumo já expostas.

Como que condicionados pela dinâmica, nossos comportamentos ocorrem na lógica dos valores individualistas e consumistas e das relações de poder do conhecimento e do poder econômico. Instauram, em alguma medida, as relações de dominação entre pessoas, grupos, nações, e geram diferentes formas de não acesso a bens sociais e consequente degradação ambiental, como a penúria. A pobreza é uma das mais graves condições geradoras de problemas ambientais: a ocupação de encostas, os esgotos sem tratamento, resíduos não selecionados, as doenças da pobreza, a escassez energética. São os efeitos que atingem os ecossistemas - que são usados como padrões referenciais para os julgamentos sobre o futuro (Medina, 20 I I).

Objetivamente, a crise socioambiental pode ser descrita como um problema de destruição, pelos homens, de uma biosfera, ou seja, de um macro sistema de autorreguladores. É desse cenário que surge a necessidade de análise e apreciação dos princípios e das ações que levaram ao desequilíbrio. Por tratar-se de um cenário de relações, chega-se à ética. No lugar de analisar ou apresentar uma construção a partir da filosofia da natureza, e assim sobre a natureza, é plausível uma interpretação na perspectiva posicional. Ou seja, não se indaga a relação de um todo com uma parte da ecologia com o homem, mas de uma posição que está na própria relação. Foi isso que Jonas realizou com suas reflexões filosóficas. Ora, se relação for um caráter que possa ser intelectualmente compreendido como coexistência, correspondência, interação, conexão e trocas, estaremos diante da proposição fenomenológica que Jonas descreve em ações de responsabilidade pela vida (Jonas, 2004).

O ensurdecer é parte do desenvolvimento científico-tecnológico alcançado a partir da segunda metade do século $X X$, que permite ao homem acabar e destruir todas as condições de vida no Planeta. Por isso, o que está em jogo aqui é a relação humana com a natureza, com a técnica e tecnologia, mas, especialmente, consigo mesmo. 
que se quer verificar é se essa atitude e/ou postura ocorre na mesma razão da instrumentalidade, ou se é possível inaugurar uma possibilidade que esteja para além dela: de convivência positiva com a natureza viva - humana e não humana - e as suas manifestações materiais e imateriais, definindo-a em patamares mais elevados do que nós, idealmente denominados como seres humanos. Jonas acredita possível.

Nesse cenário de degradação, muitas vezes denominado progresso, foram paulatinamente deteriorando os recursos naturais, as espécies vivas animais e vegetais, porém, a partir de um profundo esvaziamento da essência do humano, do cuidado. ${ }^{2}$ A modernidade nasce sob o signo da ruptura, ${ }^{3}$ da dicotomia, da oposição, também a relação homem-natureza se torna mais complexa. A ruptura conceitual que orienta a ciência e a produção dos objetos resulta hoje, paradoxalmente, num excesso de proximidade, numa dependência humana da natureza artificial possibilitada pela técnica. Há sensações psicológicas de não possibilidade de vida sem os objetos da técnica e, mesmo concretamente, a técnica permite a manutenção da vida, como, por exemplo, extensores colocados em veias e artérias ou o conforto e correções de ordem física como nos casos das peças protéticas, próteses oculares e implantes de toda ordem. Assim, na contramão do termo, a oposição homem-natureza se dá também pelo excesso de proximidade, por um processo extremo de aproximação, pela artificialização do mundo da vida: a natureza desnaturalizada.

\section{O PRINCÍPIO VIDA}

Segundo o próprio autor, a obra realiza uma interpretação ontológica dos fenômenos biológicos (JONAS, 2004, Prefácio) e o faz movido pelo fato de que quase exclusivamente as reflexões filosóficas têm se centrado no homem, atribuindo-lhe especial valor; ou na sua existência orgânica, resultando numa incapacidade de notar a "linha divisória" entre o animal e o ser humano, além de se privar do que de bom e bem há na autopercepção.

Suprimir essa dicotomia leva ao desaparecimento da distinção "animado" e "inanimado" e muda a abordagem do sentido da vida, uma vez que é explicada, exclusivamente, por intermédio da matéria. Desde Descartes, essas duas dimensões ou substâncias (Res cogitans $\times$ Res Extensa) são cultivadas artificialmente em separado,

\footnotetext{
${ }^{2}$ Ver Heidegger. Ser e Tempo. Parágrafo 32 em diante.

${ }^{3}$ O surgimento da razão ocidental promove a ruptura entre o mundo da vida e o mundo da matemática, dos símbolos, Fé versus Razão; Religião versus Estado; Homem versus Natureza; Mente versus Corpo. Ver FERREIRA Jr., Wanderley A Crise da Ética e a Necessidade da Reconstrução de Um Novo Tipo de Ethos. Intuitio, Porto Alegre, Ano 2, dez. 2009. p. 377-399 Disponível em: <http://revistaseletronicas.pucrs.br/ojs/index.php/intuitio/article/view/5967>. Acesso em 30 abr. 2016.
} 
quando, segundo Jonas, se completam e se ajudam mutuamente, pois, separadamente, sofrem tanto a compreensão do ser humano quanto a vida extra-humana.

Em decorrência disso, procura suplantar as barreiras antropocêntricas da filosofia e os obstáculos materialistas das ciências naturais, porque "no mistério do corpo vivo as duas estão unidas" (JONAS, 2004, p. 275). Para ele, as contradições com as quais o homem se depara, quais sejam, a liberdade versus necessidade, autonomia e independência, relações e isolamento, eu e o mundo, encontram-se prefiguradas em todas as manifestações da vida, das mais simples às mais complexas, e se mantêm em precário equilíbrio: entre ser e não ser, trazendo já, e desde sempre, dentro de si, um horizonte de transcendência. (JONAS, 2004)

No transcorrer do Princípio Vida, encontramos a investigação do desenvolvimento das funções e capacidades orgânicas: metabolismo, movimento e apetite, sensação e percepção, imaginação, arte e conceito - uma escala ascendente de liberdade e risco que culmina no ser humano, o qual talvez possa "chegar a uma nova compreensão da sua unicidade quando deixar de considerar-se um ser metafisicamente isolado" (JONAS, 2004, p. 13). A vida nos é apresentada e descrita como uma aposta e um risco que, na versão e na forma de vida humana francamente destinada à liberdade pode levar-nos ao desastre ou ao êxito.

Para desenvolver a temática de uma filosofia da vida, Jonas afirma que a hipótese preliminar é que esta tenha como objeto a filosofia do organismo e a filosofia do espírito. $\mathrm{Na}$ "afirmação de que mesmo em suas estruturas mais primitivas o orgânico já prefigura o espiritual, e mesmo em suas dimensões mais elevadas o espírito permanece parte do orgânico" (2004, p. II ), afirma ser impossível a um filósofo, por decorrência, a qualquer humano, supor que o majestoso cenário da vida na Terra seja um processo cego. Isso no sentido aleatório, acidental, na forma de espécies, e que este movimento vá também causalmente provocando os "fenômenos subjetivos" que acompanham os resultados físicos,

uma vez que a matéria manifestou-se desta forma, isto é, que ela efetivamente organizou-se desta maneira e chegou a estes resultados, o pensamento não pode deixar de fazer-Ihe justiça, reconhecendo a possibilidade de que o que ela chegou a realizar está disposto em sua natureza primitiva (JONAS, 2004, p. I I ).

Ao Princípio Vida, não importa estudar a história da origem da vida, tampouco do seu desenvolvimento nas suas múltiplas formas e graus de complexidade que, especialmente nos animais, se percebe, tanto de forma quanto de funções de refinamento de sentidos físicos, de ativação de instintos, de capacidades de controle de funções e atuação até a reflexão - a hierarquização é evidente. Para tanto, não é necessária a ideia de evolução, pois o sequenciamento escalonado de depósitos de camadas dependentes das anteriores proposto por Aristóteles será sempre indispensável para interpretar as funções orgânicas que podem ser explicadas de duas 
maneiras: a) a partir dos conceitos de percepção - saber, ou seja, ordem crescente de amplitude, de clareza da experiência que leva à objetivação da totalidade no ser humano; e b) dos conceitos de ação-poder, que levam ao grau crescente de ação sobre o mundo, a graus progressivos de liberdade de ação.

Essas duas maneiras culminam no pensamento humano e aparecem nele quando se pergunta: "Qual o lado que existe para o outro? É a contemplação para o agir, ou o agir para a contemplação?" (JONAS, 2004, p.276). Essa cogitação, esse pensar sobre uma alternativa transforma a biologia em ética. Independente da resposta permanece um aspecto incontroverso: Há uma escala crescente que vai do reflexo sensitivo a um saber, que se torna cada vez mais intenso; por decorrência, o saber aumenta na exata medida, a partir de uma confusa e frágil percepção, iniciando numa impressão primitiva, na base da escala animal, onde é experimentada, mesmo que germinalmente, alguma ordem de alteridade, ou seja, de relação, tornando-se progressivamente subjetiva, particular, provocando uma resposta também subjetiva.

Do que consideramos anteriormente, podemos expressar que a liberdade pode estar relacionada à percepção e à ação ou, dito de outro modo, segundo os conceitos saber e poder. A liberdade se encontra precisamente entre estes solos: o espírito e a vontade, e que, além disso, a liberdade está para o agir, e não para a dimensão do receber (JONAS, 2004). Se, como disse Jonas, o espírito, o saber e a percepção estão prefigurados na vida orgânica, também a liberdade necessitará estar.

Assim, afirmou que já no metabolismo, que é a camada mais básica da existência orgânica e usualmente ligada ao automatismo dos processos químicos que ocorrem no interior dos organismos, a liberdade está presente, ou como afirmou: "[...] ele é efetivamente a primeira forma de liberdade" (Ibidem, p. I3). Jonas alerta que devemos nos afastar de todas as associações de significados. Temos de entender que liberdade designa restritivamente "um modo de ser capaz de ser percebido objetivamente" ( $p$. 13), isto é, uma forma de existir que seja atribuível e compartilhada por todos os membros dos designados orgânicos, sem que seja compartilhada pelos demais. Mesmo assim, não poderá deixar de estar relacionada com os outros significados que atribuímos à liberdade na esfera humana, ademais, foi justamente dela que foi tomado o conceito. Isso porque também aqui, como foi para o espírito, a vontade, o princípio da liberdade brota e se "expressa" a partir de uma forma elementar, primordial, e se desdobra e se estende às mais amplas formas da dimensão subjetiva.

A pressuposição defendida tem seu relevo na ideia de que se tornar orgânico, manter-se vivo a despeito da ameaça da morte põe em foco o atrevimento original da liberdade. Vejamos:

A hipótese que me parece mais convincente é admitir que já a própria passagem de substância inanimada para substância viva, a primeira auto-organização da matéria em direção à vida, foi motivada por uma tendência a estes mesmos modos de liberdade que se manifestam no mais profundo do ser, e a que esta 
passagem abriu as portas. Essa suposição se toca com a concepção de todo substrato inorgânico de onde se ergue o edifício da liberdade (JONAS, 2004, p. 14).

Entretanto, a prerrogativa da liberdade traz consigo o risco da existência, ou seja, o "não ser". Se o organismo se contrapôs ao mundo, à integração geral, adquire independência contraditória em relação à matéria em geral, pois, mesmo assim, essa matéria lhe é necessária, imprescindível, mesmo que se distinguindo dela. Esse é o duplo movimento do metabolismo de afastar-se e manter-se condicionalmente vinculado à matéria para manter-se vivo; esse movimento para ser, embora esteja sempre sob iminente ameaça de não ser, o ser vivo necessita afirmar-se e essa afirmação "é a existência como desejo [...] uma possibilidade imposta, que continuamente precisa ser reconquistada ao seu contrário sempre presente, o não-ser, que inevitavelmente terminará por devorá-lo" (JONAS, 2004, p. 14- I 5).

$\bigcirc$ ato de existir, de ser, será sempre um fato ambíguo, manifestamente feito de antíteses do porte de "[...] ser e não-ser, de eu e mundo, de forma e matéria, de liberdade e necessidade [...]” (2004, p. I 5). Essas são formas de relação, porque viver é estar relacionado com algo e provoca um ir além, um superar, ultrapassar por parte daquilo que nutre a relação. Dessas dicotomias, ser e não ser é a basilar, a mais radical. Nelas está expresso o maior empenho, qual seja, o de prosseguir, permanecer, de não ter fim, mesmo que este fim previamente seja certo. "[...] o fato de a vida ser mortal constitui sua contradição básica, mas este fato é inseparável de sua essência sem que seja possível sequer imaginar-se que seja possível suprimi-lo" (p. I5). A relação é do tipo forma-matéria: dependente da realidade externa, mesmo que autônoma, que busca o contato capaz de extingui-la por sua falta ou por seu excesso, permanentemente perturbada em seu processo de viver. Para ser, não poderá fracassar, uma vez que é vulnerável em suas funções que só possuem eficiência num todo organizado. Poderá ser extinta a todo o momento. É exatamente essa temeridade que "põe em foco a ousadia original de liberdade que a substância assumiu ao tornar-se orgânica” (2004, p. 16).

Se a relação é do tipo forma-matéria, devemos também considerar a forma como elemento de liberdade. Embora autônoma, a forma possui um caráter constitucional à vida. A forma é essencial à vida, enquanto a matéria é acidental. Essa independência da forma viva se expressa primeiramente por uma característica: sua substância material não é dada de uma vez por todas; a igualdade não lhe é peculiar, ao contrário, há um fluxo permanente com o ambiente externo, um receber e expelir. A substância material da forma viva é dependente da função que lhe é própria, a qual a mantém e permite que permaneça ela mesma. Senso contrário, nos seres não vivos, a forma é um acidente da matéria que é permanente. No ser vivo, a forma é ativa, viva e organizada, e os conteúdos materiais é que são mutantes e se constituem estados de seu ser. Esse Ser permanece o mesmo, idêntico durante todo o seu tempo vivo. Desse modo, a 
liberdade básica do ser vivo está justamente nessa certa independência da forma com relação à sua própria matéria.

O pensamento mecanicista enfatizou a matéria extensa: Tudo o que era possível de ser medido e todas as características podiam ser explicadas, uma vez que eram passíveis de atender aos ditames do conhecimento exato. Como é o conhecimento que determina o conceito de natureza, a não vida, o não ser, que é passível desses atributos de mensuração, passou a ser a regra, mas não a vida. "E a vida uma exceção e um enigma". (JONAS, 2004, p.20) Discutir teoricamente o problema da vida somente confirma que a morte é o status natural, ou seja, que se explica por si só. Essa situação, essa contradição deriva do fato de se ter retirado a vida do conjunto da natureza.

A partir do século XVII, adotou-se um modelo mecanicista e determinista de natureza, regido por leis matemáticas. A ciência moderna se ocupou em explicar como cada estrutura estudada funcionava. A análise dos seus componentes, sua matéria e os movimentos demonstravam seu efetivo funcionamento com base num padrão. Também o cosmos era uma máquina que uma vez posta em marcha continuaria indefinidamente em funcionamento, ou na mesma corrente, mas em outra direção: a reconstrução, ou seja, "o surgimento desses sistemas a partir de estados prévios" (2004, p. 50), com a mesma base, pois o sistema estável resultante seria derivado, por si mesmo, de um passar do tempo. Seria uma estabilização sem a participação de um ser criador - ou planificador - desta ordem; de Deus: o impulso criador. Assim, "o lugar de uma criação transcendente e construtiva passa a ser ocupado pela série inteira em seu infinito prolongar-se" (2004, p. 5 I). Aqui, o ser se equipara com a ação ou com o processo. $\bigcirc$ movimento passa a ter papel central, e o resultante desse tempo, o equilíbrio, torna as situações elementares, primárias, originárias, menos superiores ao produzido, que será interpretado como mais complexo em articulação e estrutura. Esse aspecto constitui uma inversão total à ordem do pensamento clássico, o qual afirmava que a causa deveria conter mais força, pujança, mais perfeição. No entanto, estamos sob o império da razão analítica cartesiana, da inteligência cega, que apenas divide, separa, isola, fragmenta.

A liberdade, na sua forma mais elementar, como descrito, versa na independência da forma com relação à sua própria matéria. Isso incide sobre sua identidade, à da autocontinuação, ou seja, aquela tida por intermédio do ininterrupto processo metabólico. Os seres vivos têm corpo e são corpo. A inalterabilidade ou mesmidade, como prefere Jonas, do organismo vivo é distinguida pela individualidade e diversidade desconcertante num conjunto de seres homogeneamente relacionados entre si. A mesmidade qualifica como estranho, como contrário a tudo quanto se encontra além dos limites do organismo. O estranho é o mundo no qual o organismo é contra e por meio do qual necessita manter-se. Éaí que está potencialmente a liberdade.

A partir do conceito de liberdade, temos condições de orientar a tarefa de interpretar a vida. A liberdade orgânica é um poder-ser e um dever. $\bigcirc$ metabolismo é uma obrigação. Não exercê-lo cessa a vida. Há liberdade para fazer, mas não para 
omitir. O Ser é soberano sobre a matéria e, em igual tempo, se sujeita à matéria. "[...] esta necessidade é uma característica da vida não menos única do que seu poder, de que ela apenas representa o outro lado: a própria liberdade é sua peculiar necessidade". (JONAS, 2004, p. 108)

Além disso, outro traço peculiar à vida é o fato de que, para trocar matéria, a forma viva também precisa dispor dela. Todavia, ela está fora de si, está no mundo, numa relação curiosa de dependência e poder. Estar ativa para adquirir a matéria nova de que tem necessidade é fundamentalmente abertura para uma realidade externa. A vida é relação. $\bigcirc$ campo dessas relações, de ser-dependente, indica também o campo, o cenário de suas possibilidades de realizações, de intencionalidade como "caráter básico de toda a vida" (JONAS, 2004, p. 109). Em estágios cada vez mais elevados de complexidade e possibilidades de realizações, criam-se as condições de transcendência.

Essa instância de transcendência é interior e subjetiva. A interioridade pode ser entendida como sensação, sensibilidade, resposta a um estímulo, tendência, busca. Mas, mesmo na mais ínfima matriz, se acha o interesse total, irrestrito do organismo em continuar existindo, e isso é sensitivo, ou seja, faz sentir e produz impressão. Essa abertura significa comprometer-se, afetar-se, e é percebida, sentida como uma mensagem. É internamente assumida como algo que provém do outro. Desse modo, na forma de interesse instigado pela necessidade, o ser vivo procura o outro, assim como a presença não solicitada, pedida, necessária, por isso estranha do outro, desperte-Ihe repulsa, mesmo que pela sensação. É certo que essa autotranscendência tem seu substrato na necessidade orgânica e, por isso, é como uma compulsão para fora. Entretanto,

este lado passivo da mesma transcendência, coloca a vida no estado de ser "eletiva" e "informada", em lugar de ser apenas uma cega dinâmica [...] pelo fato de estar aberta para fora, passa a ser pólo (sic) subjetivo de uma comunicação com coisas que são mais estreitas que entre unidades meramente físicas e assim, a partir do isolamento do próprio sujeito orgânico, surge o exato oposto do isolamento (JONAS, 2004, p. I l0).

Segue-se a isso ainda a existência de um esquema temporal. Por meio da transcendência do imediato orgânico, ocorre abertura para sua continuação, pela busca mais fundamental da sobrevivência. Trata-se de um projetar-se no futuro, a partir de certa medida de memória, que certamente não pode deixar de estar presente como que numa identidade subjetiva que lhe vem do passado, mesmo que de curtíssimo tempo. Relativamente a esse aspecto, na forma viva humana, há uma recorrência em se falar do presente existencial, do tempo presente, como se essa dimensão fosse independente e, por si só, tivesse um "direito próprio". Todavia, o presente é situacional. Como dimensão, constitui-se totalmente por intermédio da relação com o passado e o futuro. Para nossa empreitada, esse aspecto é especialmente relevante, pois 
estamos a tentar uma descrição relacional.

No viver, no existir, não há espaço para contemplação do presente. Há um passado de onde viemos e um futuro para onde vamos; entretanto, o presente é o momento crítico, é o instante determinante do conhecimento e das decisões, da mudança. É o presente que externaliza a crise. $\bigcirc$ agora põe o pensamento, consuma a ação ${ }^{4}$.

Como disse Jonas, o presente existencialmente

é o presente da "situação" que é constituído integralmente através da relação com o futuro e o passado autêntico". Ele refulge à luz da decisão, quando o projeto de futuro regressa do passado dado (ao ser-lançado), nesta dando origem ao "presente"- que por sua vez é um produto dos dois outros êxtases temporais, uma função de seu incessante dinamismo, e não uma dimensão própria da permanência (2004, p. 249).

No presente, isolado do passado e do futuro, o ser-aí, o humano de Heidegger (2002), é inautêntico e se expõe pelo falatório, pela curiosidade, pela ambiguidade, e resulta no modo impessoal de existência, no ser decaído. Na decadência, há um enfraquecimento do ser, uma existência precária, um dinamismo ofegante, impreciso, sem orientação, feito de tendência, moda, mas que possui grande força atrativa na contemporaneidade. Por assim dizer, o homem está envolvido no dinamismo, no "corre-corre", como uma falsa presença. Esse mesmo sentido de ser se mantém para a natureza: como simples, vulgares, coisas naturais.

Essa desvalorização existencialista da natureza, no dizer de Jonas (2004, p. 25 I e seguintes), é manifestamente uma resultante do seu esvaziamento espiritual impresso

${ }^{4}$ O objetivo básico da analítica existencial de Ser e Tempo é a constituição de uma ontologia fundamental, daí a necessidade de retomar a questão do sentido e verdade do ser a partir de um novo horizonte - o tempo, e de uma nova base, a existência humana. Contudo, segundo o próprio filósofo, a questão do sentido e verdade do ser exigiria a realização de duas tarefas: realizar uma analítica existencial dos modos de ser originários do Ser-aí e estabelecer um confronto sistemático crítico com a tradição metafísica, removendo as camadas que cobrem as experiências originárias do ser entre os gregos. A analítica de Ser e Tempo desdobra-se nas seguintes teses: $\bigcirc$ homem é um ser =aí [Dasein]; a constituição ontológica fundamental do Dasein é ser um ser-nomundo. O ser-no-mundo é cuidado, o que determina sua finitude enquanto ser para morte. A abertura originária do Dasein ao mundo, ou seja, o aí do ser-aí, é constituído por existenciais que se dão numa dimensão pré-reflexiva, ou seja, antes de qualquer percepção e apreensão conceitual, racional do mundo. Esses existenciais constitutivos da abertura originária do homem ao mundo são: a disposição [Befindlichkeit], a compreensão [Verstehen] e o discurso [Die Rede]. Contudo, antes de tudo e na maioria das vezes, o homem está sob a ditadura do impessoal, imerso numa curiosidade em busca do mais novo e num falatório que nada diz. (FERREIRA Jr., 2011) 
pela ciência natural moderna, e esta possui alguma coisa em comum com o desprezo da natureza. Disse também que nunca - segunda metade do século $X X$ - uma filosofia preocupou-se tão pouco com a natureza. É como uma neutralização desta, como se não nos pudesse "dizer" nada, que não se "preocupe", que somente ao humano fosse dada essa capacidade. Está justamente na acentuação dessa diferença o fato de que "o antropomorfismo foi tão radicalmente banido do conceito da natureza que mesmo o ser humano não pode mais ser entendido antropomorficamente, uma vez que ele é apenas uma causalidade dessa natureza. Como produto do indiferente também o seu ser tem que ser indiferente" (p. 252).

Pode-se dizer que os vivos - por extensão o homem - são temporários, mortais. Pelo espaço de tempo que vivem, gozam de uma mesmidade única, particular, conferida por sua forma singular. "Seu tempo é irrepetível, feito de presentes fugazes, cujo resultado carece de contínuas novas decisões, reafirmando de modo contínuo o seu vir-a-ser que lhe é livre exercer, mas imposto para continuar existindo" (Medina, 201 I, 98). Assim, ao existir, aceita as condições sob as quais foi concebida a vida, melhor dizendo, a vida é possível. Disso tem-se que, de fato, não há qualquer indício, exceto de ordem transcendente, que se tenha o direito ou o dever de continuar vivendo. Poderia haver o nada no lugar de algo. A vida não é um axioma, mas um mistério. Por alguma razão, o mundo existe. Tendo sido a vida entregue, recebeu aquilo que lhe poderia caber: a vida. Sendo vida, renunciou ao não ser, sendo preciso rejeitar a sua vulnerabilidade. Presentemente, pertence ao ser humano o dever de manter as condições à manutenção da vida.

Se há um perigo iminente que ameaça o mundo vivo, este perigo é representado por nossa tecnologia, feita pelo conjunto de conhecimento e princípios científicos e dada racionalidade. A vida corre o perigo que jamais correu. Isso está claro e cremos que este não pode ser enfrentado por nenhuma moralidade oculta de natureza privada, mesmo como já escrevemos, não podendo inferir que tenhamos qualquer obrigação incondicional de que o ser humano tenha de existir; até porque o desaparecer, assim como o surgir, faz parte da evolução. (JONAS, 2004)

E as futuras gerações? Que direitos têm às condições de existência? Em princípio, sob as normas vigentes do direito humano, somente o que é tem direito de ser, logo, as futuras não teriam nenhum direito antes que existam. Entretanto, junte-se à questão o aspecto temporal e veremos que o que está em jogo é uma causa eterna, sempiterna, a continuidade do mistério da vida; daí a responsabilidade sobre a possibilidade de a vida ser eterna. Esse aspecto de nossa responsabilidade só pode ser contra a possível tentação fatalista. Essa condição sim é capaz de diminuir nossa capacidade de pensar e agir, dando-nos a impressão de que de nada vale relativamente a nossa relação. Essa condição paralisa.

Como então se configurará essa responsabilidade humana? Quais seus desafios? Jonas (2004) diz que é de dupla orientação. Relativamente ao efeito de nossas ações, pode-se dizer que se estendem para o futuro que pode ser mais ou menos distante, até 
extinguir-se. Essa orientação tem as condições restringidas pela nossa previsibilidade e pela complexidade das coisas do mundo. Trata-se da finitude física. Outra orientação que se alarga incide no domínio da eternidade, "onde ela jamais se perde", e que possui "a segurança de normas que se podem conhecer. Não são estranhas ao nosso coração" (p. 270). Em síntese, uma responsabilidade é de ordem moral, e outra de ordem metafísica.

Entretanto, na situação atual, é interessante observar que ambas as orientações convergem uma para a outra, pois há ameaça total do futuro, e este se põe num patamar mais elevado que o de proteção física. Ou seja, não é mais o momento de decisão sobre os efeitos em âmbito individual, isolado, próximo e no contexto das relações temporais de curto prazo, mas um momento da espécie humana no seu agir social global. Esse aspecto requer uma ética baseada na doutrina de deveres, além de uma demanda do conhecimento científico, pois requer como nunca o conhecimento das consequências.

Desse modo, a tarefa que se impõe é nova, pois "a filosofia do espírito incluiu a ética - e pela continuidade do espírito como organismo e do organismo com a natureza, a ética passa a ser uma parte da filosofia da natureza" (JONAS, 2004, p. 27I). Essa imposição se contrapõe ao sistema de crenças, às práticas e à ética da contemporaneidade que está embasada na premissa que somente o humano é fonte de toda exigência ou dever a que ele possa considerar-se obrigado. Estamos preparados para responder por ações que ultrapassem a extensão de nossas vidas? É possível ultrapassar os limites da mudez que impusemos à natureza e à vida, e ela - natureza se constituir fonte de exigência e dever?

A perspectiva biológica refletida até aqui, segundo Jonas, é a de que somente uma ética fundada no ser, na manutenção da vida, na custódia da existência, pode ter um sentido efetivo, concreto e essencial. Pelas exposições feitas, o homem, de fato, terá de assumir o enfoque orientado à decisão e à ação, a partir da abordagem do princípio responsabilidade.

\section{O PRINCÍPIO RESPONSABILIDADE}

Foi somente depois de 1966, quando se afastou da docência, que Jonas passou a dedicar-se à formulação de sua obra basilar: O princípio Responsabilidade: ensaio de uma ética para a civilização tecnológica. Como o nome indica, formulou-se ali a ética para o ser humano da nossa era, da era tecnológica. A pluralidade de orientações que norteiam a obra expõe claramente uma formação fenomenológica, pois guia sua escrita a partir da ética nos aspectos próprios da alteridade de Emmanuel Lévinas ( 1906-1995). Ao invés de tratar o outro como gostaria de ser tratado, é o outro que deveria impor a conduta adequada, pois tudo começa pelo direito do outro e pela coação a esse respeito. A orientação de Jonas (2006) segue o mesmo sentido quando escreve:

Todos os homens, diz-se, almejam a felicidade. [...] Mas é preciso reconhecer 
que a busca da felicidade não é fruto de escolhas voluntárias, e o fato de que ela se encontra enraizada de modo tão universal em nossa natureza provoca no mínimo uma forte presunção de que esta seja uma busca legítima. Se ela não indica uma obrigação, pelo menos indica um direito: se não temos a obrigação, pelo menos temos o direito de buscar a felicidade (desde que respeitemos um certo número de condições). Mas daí, por sua vez, resultaria então em obrigação - ou seja, um dever - de respeitar no outro esse direito, de não impedi-lo, portanto, e talvez até promovê-lo. É o interesse do outro, que eu devo respeitar, poderia ter consequência (sic) indireta para mim o dever (caso ele já não exista imediatamente) de também promover a minha própria felicidade, cuja limitação poderia perturbar a felicidade comum (JONAS, 2006, p. 144).

Jonas acolheu também as ideias de Heidegger quando postulou que não há porque romper com a tecnologia, mas usá-la responsavelmente quando diz, por exemplo:

Conter tal progresso deveria ser visto como nada mais do que uma precaução inteligente, acompanhada de uma simples decência em relação aos nossos descendentes. Se não o fizermos, a natureza fará, de maneira terrível. Mas, quando contestamos a viabilidade e a inocuidade desse progresso, bem como o seu caráter desejável stricto sensu e a sua concepção de homem como um todo, no futuro assim como no passado, já nos movimentávamos no terreno da teoria ética. Se estivéssemos no caminho certo, já teríamos atingido seus fundamentos, pelo menos de um ponto de vista negativo, e dirigido o olhar para a positividade. Do jeito que estão as coisas, durante certo tempo a postura positiva implicará desempenhar-se, antes de tudo, de funções de preservação e proteção, no seio da qual poderão exercer-se as funções de recuperação e de melhoramento, embora submetendo-as sempre, no entanto, ao signo da modéstia (JONAS, 2006, p. 349).

Afirma que a capacidade de ação que temos atualmente e a extensão das consequências dessas ações é que estão a exigir novas regras de ética ou uma nova ética. A técnica moderna, praticamente hegemônica, tornou ineficazes os princípios, as marcações, os limites propostos pelas éticas tradicionais.

Em termos éticos, os preceitos religiosos ou o peso da lei ou dos costumes não são suficientes para fazer frente ao intenso, enérgico e pujante, impetuoso, formidável e poderoso agir humano. Dizia que mesmo a ética do amor ao próximo, com os benefícios da honra e da justiça e mesmo da misericórdia, não tem se mostrado efetiva, ou seja, com capacidade de produzir um efeito, neste caso positivo, sobre a realidade percebida de maneira tão desarmônica, ora acima ora muito abaixo dos componentes éticos. As civilizações passadas não tiveram nenhuma experiência que se aproximasse dessa grande força, desse poder de ação, de abundância de bens materiais. Para o filósofo, foi esse excesso de sucesso - possibilitado pela técnica de se autoaperfeiçoar - que se transformou em possibilidade de o homem destruir a sua espécie e as demais 
formas de vida na terra. Há um vácuo, uma lacuna, um hiato, um nada de ética, diz Jonas.

Na obra Princípio Responsabilidade afirma que, fossem quais fossem as diferenças de conteúdo, as máximas da ética tradicional demonstram um confinamento à dimensão humana (Antropocêntrica). Por exemplo: "Ama o teu próximo como a ti mesmo"; "Almeja a excelência por meio do desenvolvimento e da realização das melhores possibilidades da tua existência como homem"; "Submete o teu bem pessoal ao bem comum"; e complementa: "Os que vivem agora e os que de alguma forma têm trânsito comigo são os que têm alguma reivindicação sobre minha conduta, na medida em que esta os afete pelo fazer ou pelo omitir" (JONAS, 2006, p. 36). $\bigcirc$ que caracterizava a ética, até o presente momento, no trato com o externo ao homem, era eticamente neutro, tanto do ponto de vista do objeto quanto do sujeito, do agir humano, porque a techne só afetava superficialmente a natureza das coisas. Assim, não se colocavam questões acerca de danos duradouros à integridade do objeto ou da ordem natural. A velocidade e os efeitos dessas mudanças extrapolam as condições, as qualidades e as contribuições de cada um dos atos de seus contribuintes (cientistas, usuários, filósofos), além de ocorrerem em meio a situações completamente novas, sem precedentes, como bombas e contaminações.

Diante disso, os ensinamentos da experiência, da ética-prática e do ethos-costume ethos-hábito, são pouco potentes. Portanto, pode-se entender que o bem e o mal agir com o qual o homem tinha de se preocupar, num modelo cultural de baixa tecnologia, não demandava uma previsão de longo prazo, um planejamento, porque a ação ou o alcance efetivo desta era em tempo e espaço próximos. Ou seja, a práxis tinha seus critérios e consecução quase que imediatos. As consequências se perdiam no tempo, ao sabor do tempo, do acaso, do destino, da providência divina. Portanto, a ética tinha a ver com o tempo presente, com situações circulares, com contornos típicos e recorrentes.

Os limites da moral se configuravam na contemporaneidade, num horizonte longínquo do tamanho de uma vida, na fronteira espacial das relações familiares, da vizinhança, do trabalho, ou seja, no campo das suas relações e papéis sociais dessa esfera de ação que era boa ou má, num contexto de decisão de curto prazo. Não são problemas com identificação de autoria da ação; a moralidade é inerente a essa própria ação, tanto que não há julgamento de responsabilidade por efeitos involuntários ou tardios de um agir bem-intencionado, bem-executado, como, por exemplo, de uma morte em consequência de complicações num pós-operatório.

\section{UMANOVAÉTICANASCIDADO PERIGO}

"A ética tem de existir, porque os homens agem, e a ética existe para ordenar suas ações e regular seu poder de agir" (JONAS 2006, p. 65). Há um tempo, nem tão remoto, a técnica era um atributo, um predicado cobrado pela necessidade humana, um meio adequado a fins próximos, e não um caminho escolhido pelo homem como um fim, na atualidade é outro o cenário. 
homem tornou-se poderoso e perigoso demais para si e para a natureza, para a biosfera. Não é possível a vida na natureza artificial criada pela tecnologia e, mesmo que fosse, a vida gerada pelo poder criativo da natureza, em sua evolução e agora em nosso poder, ainda assim, teria o direito de clamar por proteção. Numa perspectiva verdadeiramente humana - humanus, humus - fértil, a natureza conserva sua dignidade que se contrapõe ao nosso poderio,e, uma vez que nos gerou, devemos fidelidade à totalidade de sua criação (JONAS, 2006). Qualquer ênfase antropocêntrica, que enfatize e destaque o homem e nos diferencie da natureza, é reducionista e desumanizadora.

A composição de deveres e obrigações relativamente à natureza levou-nos a priorizar o humano, afinal a compreendemos quase sempre como estando à disposição, como objeto de uso particular. Entretanto, se o dever em relação ao homem tem caráter prioritário, não será necessário incluir o dever em relação à natureza como uma condição à própria existência humana e também como um dos componentes da sua integridade existencial? O perigo comum que natureza e homem correm nos permite descobrir uma nova dignidade própria da natureza, que nos chama a defender seus interesses para além da relação instrumental que temos estabelecido comela?

As éticas usadas, a partir de Aristóteles à contemporaneidade, apresentaram-se como sistemas centrados no homem. A relação ética se dá de homem para homem. Nunca entes não humanos ou relações extra-humanas foram objetos de dever. $\bigcirc$ que cabe dizer é que o humano não possui, nos padrões éticos tradicionais, nenhuma responsabilidade ética com relação a um ente natural: árvore, alga, pássaro, cervo, mar. Consequentemente, a natureza possui importância somente enquanto convém ao ser humano. Nossos parâmetros éticos tradicionais e corriqueiros são de uma ética que gira em torno dos direitos e deveres humanos. O imperativo categórico de Kant é: "Aja de modo que tu também possas querer que tua máxima se torne lei geral". O que se evoca é a razão "que tu possas" e a autoaceitação, que tem como ponto de partida a hipótese social de atores humanos, racionais em convívio. $\bigcirc$ aspecto relevante não é moral, mas lógico: poder ou não poder fazer. Isso não expressa aprovação ou desaprovação moral. Relativamente ao cenário de risco à vida e ao futuro, a infração desse imperativo não irá conduzir a nenhuma contradição, uma vez que

Eu posso querer o bem presente ao preço do sacrifício do bem futuro. Eu posso querer, assim como o meu próprio fim, também o fim da humanidade. Sem cair em contradição, posso preferir, no meu caso pessoal, bem como no da humanidade, uma breve queima de fogos de artifício que permita a mais completa auto-realização (sic), à monotonia de uma continuação interminável na mediocridade (JONAS, 2006, p. 48).

Mesmo quando é expressa alguma preocupação com o futuro do Planeta, o ativo da 
preocupação está na extinção da espécie humana. Logo, nos dois polos da relação ética está o homem em sua dimensão individual e, desse modo, não se molda uma preocupação universal com qualquer organismo, tampouco com a extensão ou consequência desse novo agir, desse novo tempo.

Jonas (2006) afirma que um imperativo adequado e esse novo tipo de agir humano e voltado a esse sujeito atuante deveriam ser:

"Aja de modo a que os efeitos da tua ação sejam compatíveis com a permanência de uma autêntica vida humana sobre a Terra" [...] ou negativamente: "Aja de modo a que os efeitos da tua ação não sejam destrutivos para a possibilidade futura de uma tal vida"; ou simplesmente: Não ponha em perigo as condições necessárias para a conservação indefinida da humanidade sobre a terra; ou, em uso novamente positivo: "Inclua na tua escolha presente a futura integridade do homem como um dos objetos do teu querer (p. 48).

Decorrem daí pelo menos dois aspectos relevantes de registro: primeiro, que as proposituras não resultam em qualquer contradição e expressão, pois objetivamente elas dizem que somos livres para arriscarmos nossas vidas, mas não a da humanidade; o outro manifesta o relevo da dimensão pública sobre a privada, não sendo o particular a dimensão causal na qual podemos aplicar esse imperativo.

O imperativo kantiano está voltado para o indivíduo, e seu critério de aplicabilidade é o momento. Ele clama que cada pessoa pondere sobre o que aconteceria se a máxima de sua ação presente se transformasse em lei geral. É a coerência, ou a falta dela, na generalização hipotética que se transforma em prova da escolha? Entretanto, em que parte se admite a probabilidade de que minha escolha privada seja lei geral, ou que essa escolha contribua para a generalização? Nesse caso, o princípio orientador não é o da responsabilidade objetiva, uma vez que, de fato, não são consideradas as consequências reais. No imperativo kantiano, há, sim, uma construção subjetiva de autodeterminação.

De outro modo, o imperativo jonasiano clama por um tipo diverso de coerência, não o do ato em si, mas dos seus resultados finais, dos seus efeitos para o prosseguimento da atividade humana, da vida humana no tempo futuro. Jonas chama a atenção para o fato de que a universalização que o imperativo vislumbra não é hipotética, ao contrário, são "as ações do todo coletivo, assumem a característica de universalidade na medida real da sua eficiência. Elas "totalizam" a si próprias na progressão de seu impulso, desembocando forçosamente na configuração universal do estado de coisas" (JONAS, 2006, p. 49). É justamente esse aspecto que se insere na dimensão moral, o horizonte temporal que o imperativo kantiano não possui, pois se desdobra sempre sobre um instante presente e abstrato, já que contava com um comportamento não cumulativo. O jonasiano toma a direção do futuro previsível e concreto sobre o qual recai nossa responsabilidade.

Há um caráter novo no nosso agir que se estende da aplicação técnico-tecnológica 
no domínio não-humano que, ultimamente, passou a vigorar sobre o humano porque aplicamos a técnica sobre nós mesmos - prolongamento da vida, controle de comportamento, manipulação genética - , especialmente sobre a natureza. Por isso, não parece mais de todo absurdo afirmarmos que o novo agir humano deva levar em consideração mais do que interesses meramente humanos. Se assim for, também nossa obrigação se alarga para esse além, e o nosso agir terá de passar a se preocupar com o bem humano e o bem do que é extra-humano, ampliando o reconhecimento de que há fim em si fora da esfera humana. Isso demandaria incluir o cuidado com esses elementos não-humanos como bem humanos. Exigir-se-ia uma nova doutrina do agir, uma nova ética.

Uma ética da responsabilidade de longo alcance, afirma Jonas (2006), proporcional à amplitude do nosso dever e, sob efeito daquela responsabilidade, também uma nova humildade, "não como a do passado, em decorrência da pequenez, mas em decorrência da excessiva grandeza do nosso poder, pois há um excesso do nosso poder de fazer sobre o nosso poder de prever e sobre o nosso poder de conceder valor e julgar" (p. 63). Assim, a contenção responsável é a melhor alternativa, tanto para nossa falta de tino como para a ignorância das consequências últimas decorrentes do potencial dos processos tecnológicos. Diante das ameaças iminentes, cujos efeitos ainda podem nos atingir, frequentemente o medo constituiu o melhor substitutivo para o adequado bom senso, para a sabedoria. Mas o medo é falho diante de uma perspectiva de longo alcance - que importa sobremaneira nesse caso - , porque a pequena dimensão das coisas em seus primórdios, na fase inicial de sua atuação e desenvolvimento, faz com que estas nos pareçam, na maioria das vezes, inocentes.

A existência da ética é proporcionalmente necessária quanto maior forem os poderes de agir que ela tem de regular, diz Jonas. Do mesmo modo, também o princípio ordenador deve se adaptar ao tipo de ação que deve regular. Se dissermos "não matarás", é porque os homens têm o poder de matar e porque de fato matam. Se hoje a natureza da capacidade de agir provém de novas capacidades, poderes de ação tecnológica, cuja utilização está posta pela própria existência delas, e se por seu vigor e potencial - as consequências potenciais - têm a capacidade de abolir a neutralidade moral da qual habitualmente gozam as interações da técnica, significa que necessitamos de uma nova ética - nascida do perigo - pois nosso agir técnico-tecnológico é novo tanto em seus objetos quanto em magnitude de seus efeitos. Esse é o pressuposto.

\section{CONCLUSÕES}

Tendo em vista o exposto, percebeu-se a possibilidade de que o comportamento humano se torne objeto de dever. Para tanto, tratou-se acerca da responsabilidade reconhecida como obrigações pela vida. Essas ideias de Jonas constituíram esse caminho expresso nas obras: O Princípio Vida: fundamentos para uma biologia filosófica e O princípio da Responsabilidade: ensaio de uma ética para a civilização tecnológica. 
princípio vida assume que a vida, em todas as suas manifestações, independentemente de sua instrumentalidade em relação ao homem, possui valor e dignidade em si. Ademais, se na atualidade a capacidade humana de agir advém de novos poderes de ação tecnológica, cuja utilização se dá pela própria existência deles, por seu vigor e potencial destrutivo, significa que a humanidade necessita de uma nova ética nascida desse perigo potencial do próprio agir humano. Este é o pressuposto da ética da responsabilidade: uma noção contrária àquela de imputação de responsabilidade por atos e suas consequências, mas pelo objeto que reivindica o agir. Nesse caso, é um agir responsável que se obriga a atos cuja justificação está fora do agente, mas na esfera de sua influência.

Trata-se de um sentimento de responsabilidade sobre algo que necessita do poder do agente, relacionado à sua competência ou sob sua dependência; uma necessidade externa que demanda, requer uma resposta e sujeita o agente a uma obrigação. Nessas condições, o agente se torna sujeito a uma obrigação, pois o poder o torna objetivamente responsável por aquele ou aquilo que lhe foi confiado. $\bigcirc$ essencial está no bem que foi confiado ao agente e que é reconhecido por ele como um dever, pois tem consciência do seu poder/dever de agir.

$\mathrm{Na}$ ética da responsabilidade, o agente e o objeto estão vinculados por uma conexão de vontade.

A espécie humana possui a particular capacidade de responsabilizar-se por algo ou por uma pessoa. Ao longo da vida, será potencialmente sujeito de responsabilidade externa. Esse traço se apresenta quase como um dever contido na espécie, como uma qualidade humana. Essa condição Ihe traz a obrigação na forma de responsabilidade contida como a própria natureza, assim como o fluxo de demandas que se apresentam de modo contínuo no existir. As assistências próprias do dever parental ou governamental se expressam de modo global, não podem sofrer descontinuidade. Essas responsabilidades não cessam nem há o fim de uma obrigação. $\bigcirc$ que está em jogo é a existência inteira da pessoa ou da identidade social a ser garantida, no caso, a governamental.

Fundamental compreender, em relação à responsabilidade como princípio ético, o futuro, que é sempre incerto, e cujos efeitos o responsável não poderá se ocupar, haja vista o limite de sua própria existência. Sobre o futuro, o papel da responsabilidade é coadjuvante, mas é justamente a causalidade da existência protegida o derradeiro objeto do seu cuidado. Ou seja, é o caráter futuro, o posterior daquilo que deve ser objeto de cuidado, que institui o aspecto mais próximo da responsabilidade: a vida de um filho, as condições de uma comunidade ou as condições ambientais nas próximas décadas.

Outro aspecto importante diz respeito ao poder. A responsabilidade é um correspondente do poder, visto que a extensão e a modalidade de poder determinam a extensão e a modalidade da responsabilidade. Os efeitos do poder geram o conteúdo do dever em resposta ao que acontece. Pode-se dizer que, se os efeitos colocam em risco as condições da existência humana, é razoável propor que, durante certo tempo e 
sob certas condições, as aspirações mais particulares, a fruição e a ética orientada à boa vontade serão substituídas por deveres impostos a nós mesmos, nascidos da vontade como elemento de autocontrole do nosso próprio poder conscientemente exercido.

Em relação à natureza, o homem chegou ao ponto no qual ele ameaça a continuidade da vida, devido à liberdade de apor fins e ao poder de executá-los. Em decorrência disso, o homem se torna o primeiro objeto do seu dever: o dever de não destruir aquilo que foi possível ser, graças às condições dadas pela natureza.

O dever com a natureza é a pré-condição da existência da espécie, não apenas por isso, mas também como solidariedade que possibilite afirmar a dignidade da natureza para além dos aspectos utilitários.

Assim, nascido do perigo, o dever clama por uma ética de preservação e proteção, contrariando a do progresso e aperfeiçoamento. Por isso, é possível afirmar que a responsabilidade é o cuidado reconhecido como uma obrigação em relação a outro ser vivo, e se torna preocupação e pré-ocupação, uma vez que há ameaça à vulnerabilidade da vida.

A natureza, a insegurança da sua existência e à do homem, a consciência do poder e da causalidade se unem no sentimento ativo de responsabilidade. Se dessa relação resultar um sentimento ainda mais poderoso, como a compaixão ou o amor, o homem aprenderá a temer pela sorte de ser amado, pelo homem ou por outro ser vivo, e cuidará do seu futuro.

Trata-se de uma mudança axiológica a ser estimulada e formada e que trilha um caminho novo, um novo tipo de relação com os elementos fenomênicos do ambiente natural e artificial.

\section{REFERÊNCIAS}

HEIDEGGER, Martin. Ser e tempo. 12. ed. Trad. de Márcia Sá Cavalcante Schuback. Petrópolis: Vozes, 2002. Partes I ell.

. A questão da técnica. In: Ensaios e Conferências: Martin Heidegger. Trad. Emmanuel Carneiro Leão, Gilvan Fogel, Márcia Sá Cavalcante Schuback. 5. ed. Petrópolis: Vozes; Bragança Paulista: Editora Universitária São Francisco, 2008. (Coleção Pensamento Humano), p. I I-38.

JONAS, Hans. O princípio vida: fundamentos para uma biologia filosófica. Trad. Carlos Alberto Pereira. Petrópolis, RJ: Vozes, 2004.

O princípio da Responsabilidade: ensaio de uma ética para a civilização tecnológica. Trad. do original alemão Marijane Lisboa e Luiz Barros Montez. Rio de Janeiro: Contraponto/Ed. PUC - Rio, 2006.

MEDINA, Patrícia. A Relação homem-natureza, a fenomenologia do cuidar e a 
dimensão formativa. 20 I I I 68 f. Tese (Doutorado) - Universidade Federal de Goiás, Goiânia, $\quad 20$ I l. Disponível e m : <https://ppge.fe.ufg.br/up/6/o/Arquivo_I_Tese_Patr\%C3\%ADcia_Medina.pdf? I 335 463790 >. Acesso em: 10 dez. 2015.

NIRENBERG, David. Choosing Life. Disponível em: <http://www.powells.com/review/2008_II_06.html >. Originalmente publicado dia 6 novembro de 2008 por Tauber Instituto para o Estudo dos judeus europeus. Acesso em: 29 abr.2016.

SIMONDON, Gilbert. Tradução de Du mode d'existence des objets techniques (Gilbert Simondon, Paris: Aubier-Montaigne, 2008 [1958]), por Pedro Peixoto Ferreira (tradução) e Christian Pierre Kasper (revisão). Introdução. Disponível em: $<$ https://cteme.wordpress.com/publicacoes/do-modo-de-existencia-dos-objetostecnicos-simondon-1958/introducao/>. Acesso em I 7 jan. 2016.

Recebido em: 18/05/2016

Aprovado em: 15/09/2016 